\title{
RECENT ADVANCES IN SCIENCE AND TECHNOLOGY \\ OF MATERIALS
}

Volume 1 


\section{EDITORIAL COMMITTEE}
M. J. Aitken Oxford University (England)
N. Brown University of Pennsylvania (USA)
G. J. Dienes Brookhaven National Laboratory (USA)
R. W. Douglas University of Sheffield (England)
J. S. Kane Atomic Energy Commission (USA) 


\title{
RECENT ADVANCES IN SCIENCE AND TECHNOLOGY OF MATERIALS
}

\author{
Volume 1
}

\author{
Edited by \\ Adli Bishay \\ Director, Solid State and Materials Research Center \\ American University in Cairo \\ Cairo, Egypt
}




\section{Library of Congress Cataloging in Publication Data}

\section{Cairo Solid State Conference, 2d, 1973.}

Recent advances in science and technology of materials.

Sponsored by the U.S. National Science Foundation.

Includes bibliographical references.

1. Solids - Congresses. I. Bishay, Adli, ed. II. United States. National Science Foundation. III. Title.

QC176.A1C3 1973

ISBN-13: 978-1-4684-3023-3

530.4 '1

74-17098

DOI: $10.1007 / 978-1-4684-3021-9$

The proceedings of the Second Cairo Solid State Conference held in Cairo,

Egypt, April 21-26, 1973, will be published in three volumes, of which this is volume one.

(C) 1974 Plenum Press, New York

Softcover reprint of the hardcover 1st edition 1974

A Division of Plenum Publishing Corporation

227 West 17th Street, New York, N.Y. 10011

United Kingdom edition published by Plenum Press, London

A Division of Plenum Publishing Company, Ltd.

4a Lower John Street, London W1R 3PD, England

\section{All rights reserved}

No part of this book may be reproduced, stored in a retrieval system, or transmitted, in any form or by any means, electronic, mechanical, photocopying, microfilming, recording, or otherwise, without written permission from the Publisher 


\section{SECOND CAIRO SOLID STATE CONFERENCE}

\section{REVIEW}

The Second Cairo Solid State Conference, sponsored by the U.S. National Science Foundation, was held in Cairo, Egypt, Apri1 21 to 26, 1973. The Conference was organized by The American University in Cairo, in cooperation with Ein Shams University, Cairo.

The Conference, whose theme was "Recent Advances in Science and Technology of Materials," followed the First Cairo Solid State Conference by seven years, and this time combined the fields of Solid State Science and Archaeology. The papers presented dealt with recent discoveries and techniques and their applications in the study of both modern and ancient materials.

From all aspects the Conference was indeed a successful one, attracting over 300 participants from 13 countries. Many of the papers included advances hitherto unreported in several fields. The "Archaeology" sessions included work on analytical techniques and dating as well as restoration and preservation studies, and the sessions on "Modern Materials" attracted papers on technology in addition to studies of the physical and chemical properties of glass, ceramics, metals, and polymers and their composites.

The final session of the Conference was devoted to a review of the papers presented. C. S. Smith (USA), reviewing the papers on Archaeology, noted the

\section{Impact of Physical Science on Archaeological Research}

"It is interesting historically to notice that the first laboratory studies of ancient artifacts were in analytical chemistry, the branch of science that first added anything to the ancient empirical knowledge of materials. Later on came petrography and metallography but only recently has the solid state physicist himself become involved. This is precisely the order in which the science of solids 
developed. For long there was no means of studying structuresensitive phenomena and the physicist completely ignored them until very recently. But it is, of course, in the fine nuances of structure that the best record of material history lies. At this Conference we have seen examples of superb analytical methods and the most recent tools of the solid state physicist being used to reveal ancient methods of manufacture in more detail than the artisan himself could have conveyed in words, and to provide the subtle but indelible 'fingerprints' revealing date and provenance.

"It was in the field of conservation that physical science first made really significant contributions to archaeology and art history, and it is still in the conservation laboratory where one finds the most sensitive overall view of historical-technical processes. In order to be able to conserve something and sometimes to restore it, one has to understand the material fully. Conservators not only do so in material terms; they are also concerned with all of the art-historical aspects of artifacts, with the individual experience of the artist and the social environment which influenced him. The conservation laboratory therefore provides an excellent arena for cooperative work of mutual interest to artists, historians and scientists."

Professor Smith also noted the

\section{Emphasis on Instrumentation}

"It is perhaps inevitable in a conference of this kind that the emphasis should be on instrumentation. The instrumentation is so very impressive, and the techniques so ingenious, that a special effort is needed to remember why the instrumentation is being used in the first place. It is easy for a scientist to think that when he has used his most wonderful gadgetry to get some nice numbers on composition or structure that this is enough in itself. Of course it is not. His figures and patterns are meaningless unless they are put into the fuller context of understanding humanity in the past and provide a new route in humanistic studies. Instead of reading books and manuscripts one now works in a laboratory to read the physical record, but this is done for the same purpose that the scholar in the past gathered information from the verbal or pictorial record. However elegant or expensive the equipment used, and however precise the results, the work is without value as a contribution to historical understanding unless this human meaning is seen."

The papers on "Modern Materials" stressed new applications of solid state science to rapidly advancing technology. Some particularly important and topical subjects reported upon were: 


\section{Special Materials for Energy Purposes}

Professor J. G. Dienes (USA) pointed out that the field of solid state science and defects in solids faces special challenges from technology. "Higher temperatures and higher exposures are required if we are going to be efficient in our energy production. If we are thinking, in the long run, of thermonuclear reactors -the so-called 'clean fuel' -- then the materials we are concerned with will have to withstand very severe conditions. A very much altered neutron spectrum will involve transmutation products, impurities, changes in stoichiometry, etc. We are faced with the necessity of using unusual materials, refractory materials, instead of the ones which we are used to. The field is moving essentially from the simple materials to the more complex materials, and a number of fundamental problems will have to be answered."

\section{Glass Fibers for Communications}

Professor R. W. Douglas (England) spoke about the situation in the spectroscopy of glasses as revealed by the contributions to this Conference. "At the First Cairo Solid State Conference, a paper was presented which summarized what was then known about the spectroscopy of glasses from the ultra violet to infrared. The spectroscopy of transition metal ions was explored, making use of crystal theory which just ten years before the 1966 Conference had begun to be used by chemists, C. K. J $\phi$ rgensen in particular. When it was first proposed that glass fibers could be used as transmission lines for a beam of light carrying communications signals, it was at least clear from what was already known about the effect of transmission of metal ions and other absorptions that the proposal should clearly not be considered impossible. Now, the idea is nearly a practicality."

Professor J. Zarzycki (France), reviewing the sessions on "Mechanical Properties," stressed the remaining problems involved in the use of glass fibers for optical communications. "It has been clearly shown that even if we succeed in producing glasses with very small absorption coefficients -- enough for communication purposes -- the problem remains of how to handle these materials. These fibers must withstand hard mechanical treatment, and they must also be stable in time. Static fatigue problems and corrosion will also be involved."

During the Conference, there was considerable discussion and general agreement on the importance of 
Cooperation Between Scientists of Different Institutions and Countries, and Between Physical Scientists and Archaeologists

Scientists involved in the study of either ancient or modern materials must, as Professor Zarzycki pointed out, cooperate in their research efforts, if for no other reason than the great expense of the instruments necessary in understanding materials. Professor Smith also referred to the advantages of cooperation, repeating one Conferee's observation that "It is not enough simply to use somebody's machine or to have him make a measurement; you must debate the topic with him and publish jointly. The days have gone by when a physical scientist doing analyses can write an appendix to an archaeological paper, reporting fine measurements that no one bothers to give meaning to. The scientist must become one of the principal authors, if not the principal author, for he must himself ask his own kind of archaeological questions. This is a superb field for cooperative research."

In conclusion, the Conference succeeded in its purpose of bringing solid state scientists and archaeologists together, and has paved the way for further interactions among them in the future. At the same time, scientists have been reminded of the challenges they face in answering the demands of a vastly changing technology, and of the citizen's growing interest in and response to technology. 


\section{ACKNOWLEDGMENTS}

The successful completion of the Conference was largely due to the encouragement and enthusiasm of the late Christopher Thoron, President of The American University in Cairo, the full cooperation of Dr. Ismail Ghanem, * President, and Dr. Nayel Barakat, Dean of the Faculty of Science, Ein Shams University, and the support of the U.S. National Science Foundation and the Egyptian Academy of Science and Technology.

The papers published in the three volumes of the se Proceedings went through two screening operations. The abstracts submitted for presentation at the Conference were refereed by a Committee including Professors Arthur Quarrell (Sheffield University), John Thomas (University of Aberystwyth, Wales), Nayel Barakat and Sami Tobia (Ein Shams University), Zaki Iskander (Department of Antiquities, Cairo), Kamal Hussein (Egyptian Academy of Science and Technology), and Hosny Omar, Farkhonda Hassan and James Heasley (The American University in Cairo). The full texts of the papers presented at the Conference were refereed by the Editorial Committee and other specialists whom they appointed.

The coordination between authors and members of the Editorial Committee was due to the skill and hard work of Marjorie Ellen Ekdawi, who also helped in typing the manuscript. Mary Dungan Megalli edited the papers for English language, organized the typing and did the proofreading. Soraya Garas, Mrs. Ekdawi, Victor Yacoub and Kamal Ragy completed these three volumes of difficult and demanding typing in just over two months.

To all the above, my sincere thanks and appreciation. Special thanks are also due to Carl Schieren and Priscilla Blakemore of The American University in Cairo, to my colleagues at the Solid State and Materials Research Center and students at The American University in Cairo, with special reference to members of the Science-Engineering Society.

Ad1i Bishay

*Currently Minister of Higher Education and Scientific Research. 


\title{
CONTENTS OF VOLUME 1
}

\author{
DEFECTS IN SOLIDS
}

Kinetics of Defect Formation in Alkali Halides at Helium Temperatures ........... 1 G. J. Dienes

Relaxation of Impurity-Defect Complexes in Fluorite Crystals . . . . . . . . . 15

J. H. Crawford, Jr. and E. L. Kitts, Jr.

Intrinsic Point Defects in Oxides with the Rutile Structure . . . . . . . . . .

R. A. Weeks

The Capture of Electrons by Negatively Charged Impurity Atoms in n-Type Germanium . . . . . 39

E. F. E1-Wahidy and A. G. Mironov

Radiation Defects in Heavily Irradiated GaAs . . . . . . 47

E. Yu. Brailovskii, V. N。Broudnyi,

I. D. Konozenko, and M. A. Krivov

\section{ELECTRICAL PROPERTIES}

The Problem of Chemical Inhomogeneities in Electronic Materials ............

Harry C. Gatos and August F. Witt

A Review of the Electrical Properties and Microstructure of Vanadium Phosphate Glasses . . . . . . . . . .

D. L. Kinser and L. K. Wilson

Electrical Switching in Calcium Phosphate Glasses Containing Iron ..........

M. H. Omar and M. N. Morcos 
Role of Iron and Electrical Conductivity in

Iron Calcium Phosphate Glasses . . . . . .

R. F. Motran, A. M. Bishay, and D. P. Johnson

Properties of Simultaneous1y Sputtered Thin

Metal Films ...............

F. Ismail and L. M. E1 Nadi

Indirect Exciton with Degenerate Valence Band

in the Two-Photon Absorption in

Semiconductors ..............

A. R. Hassan

Structure of Chalcogenide Glasses . . . . . . . . .

Norbert J. Kreid1 and Werner Ratzenboeck

Effect of Heat Treatment on Electrical Properties

and Structure of As-Te-Ge Chalcogenide

Thin Films ................ .

171

F. H. Hammad, A. A. Ammar, M. M. Hafiz,

and A. E1-Nádi

Application of Avrami's Equation to the

Conductivity Changes of Amorphous

Selenium ................

M. K. E1-Mous1y and F. E. Gani

Electrical Properties of Quenched $\mathrm{SnO}_{2}$ Films

on Glass Substrates . . . . . . . . . . .

E. W. Wartenberg and P. W. Ackermann

Physical Properties of Sputtered Amorphous

Germanium Thin Films: The Role

of Technological Parameters . . . . . . .

M. Závětová, S. Koc, and J. Zemek

\section{MAGNETIC PROPERTIES}

Some Recent Results on Paramagnetic Spin-Lattice

Relaxation in Hydrated Paramagnetic

Salts of the Iron Group . . . . . . . . .

C. J. Gorter and A. J. van Duyneveldt

ESR and Optical Studies of Induced Centres in

Binary Silver and Alkali Borate

Glasses .................

F. Assabghy, E. Boulos, S. Calamawy,

A. Bishay, and N. Kreidl 
ESR and Structural Studies on Pseudo-Alexandrite . . . .

S. Arafa, S. Haraldson, and A. Hassib

Magnetic and X-Ray Crystallographic Studies of

a Series of Nitrosodisulphonates and

Hydroxylamine-N,N-Disulphonates . . . . . .

B. D. Perlson, D. B. Russe11, R. J. Guttormsom,

and $B$. E. Robertson

RADIATION EFFECTS

Development of Materials for Energy-Related

Applications ...............

J. S. Kane

Problem Areas in the First-Wall Materials of

a Controlled Thermonuclear Reactor . . . . .

A. C. Damask

Simulation of $14-\mathrm{MeV}$ Neutron Damage to

Potential CTR Materials.

R. J. Borg

Deformation Luminescence of Irradiated CsI

(T1) Crysta1s

B. G. Heneish and L. M. E1 Nadi

A Bond-Type Criterion to Predict Bombardment-

Induced Structure Changes in

Non-Metallic Solids .............

H. M. Naguib and Roger Ke11y

\section{CHEMISTRY}

Surface Area and Pore Structure of

Low-Porosity Cement Pastes

R. Sh. Mikhail, S. A. Abo-E1-Enein

and $G$. A. Oweimreen

Adsorptive Behaviour of Alkali and

Alkaline-Earth Cations onto

Quartz ..................

Selim F. Estefan and Mounir A. Malati

Adsorption of Some Starches on Particles of Spar Minerals ............. 365

H. S. Hanna 
Sintering of Coba1t-Molybdenum Oxide Films on Alumina Supports . ........ 375

D. Dollimore and G. Rickett

Properties of Anodized Zinc in Alkaline Solutions . . . . . . . . . . 389 S. M. E1 Raghy, M. M. Ibrahim, and A. E. E1-Mehairy

Contents of volume 2............... 407

Contents of Volume 3............... 411

Index . . . . . . . . . . . . 4 415 


\section{RECENT ADVANCES IN SCIENCE AND TECHNOLOGY \\ OF MATERIALS}

Volume 1 